an abnormal smear in 1981 received satisfactory follow up. ${ }^{9}$

The rates of follow up in this study are minimum rates as we were unable to adjust for repeat smears that were examined in other laboratories in Victoria. Although a second smear test does not complete the appropriate management for women with the abnormalities described, the figures indicate a high degree of acceptance of initial management among women who lived in Victoria and their medical practitioners.

Older women adhered to the recommendations rather better than younger women. This is reassuring given the evidence that abnormalities in older women are less likely to regress and that they develop into more serious abnormalities generally more quickly than in younger women. ${ }^{10}$

The lack of a clear relation between social class and acceptance of repeat smear testing is also encouraging, indicating that if rates of participation in a screening programme can be increased among women from the lower social classes non-acceptance of the management of abnormalities should not inhibit the potential success of the programme.

The reminder letter potentially increased the proportion of women being screened substantially (by $18 \%$ in group A and $24 \%$ in group B). These results occurred in women whose adherence to the recommendations for repeat cervical smear tests was fairly high. The potential impact of reminder letters might be considerably greater where non-compliance was a more serious problem or if the letter was sent directly to the woman.

The reminder system described in this report should work in any country that provides screening for cervical cancer. Computerised record systems are desirable but not essential. To date, Australia has elected to take an opportunistic approach to preventing cervical cancer. The profile of the women being screened is biased towards younger women of high socioeconomic state. Women may elect to have their smear taken by any general practitioner, who is paid on a consultation basis. The reminder system of our service is neither labour intensive nor expensive. With the laboratory records stored on computer it is easy to program the computer to issue reminder letters at defined intervals. Such a system provides a fail safe mechanism for ensuring that reports of abnormal smears are not overlooked. The follow up section of the service is staffed by two clerical officers (out of a total staff of more than 60) and accounts for considerably less than $5 \%$ of the service's budget.

Achieving high rates of follow up smear tests and management in women with lesions that may be precursors for cervical cancer is critical to the success of a screening programme. Implementing fail safe systems for ensuring that such abnormalities are not overlooked deserves a high priority in the design of screening programmes. Funding bodies should not be allowed to believe that they have fulfilled their responsibility by providing laboratories with sufficient resources for only the initial tests. Failure to achieve appropriate management of abnormalities detected by screening tests will severely reduce the impact of the whole programme.

1 Mitchell H, Medley G, Drake M. Quality control measures for cervical cytology laboratories. Acta Cytol 1988;32:288-92.

2 Mitchell H, Medley G. Delay times to definitive diagnosis after an abnormal Pap smear. Aust N Z J Obstet Gynaecol 1987;27:283-6.

3 Pagano R, Chanen W, Rome RM, Johnstone NR. The significance of human papillomavirus atypia ("wart virus infection") found alone on cervical cytology screening. Aust $N Z$ f Obstet Gynaecol 1987;27:136-49.

4 Rome RM, Chanen W, Pagano R. The natural history of human papillomavirus (HPV) atypia of the cervix. Aust $N Z 7$ Obstet Gynaecol 1987;27: virus $287-90$.

5 Ross KN. Social area indicators of educational need. Australian Council for Educational Research Limited. Melbourne: Allanby Press, 1983.

6 Sharp F, Duncan ID, Evans DM, et al. Report of the intercollegiate working party on cervical cytology screening. London: Royal College of Obstetricians and on cervical cytology scree

Singer A. The abnormal cervical smear. Br Med f 1986;293:1551-6.

7 Singer A. The abnormal cervical smear. Br Med $\mathcal{F} 1986 ; 293: 1551-6$. Robertson JH, Woodend BE, Crozier EH, Hutchinson J. Risk of
cancer associated with mild dyskaryosis. Br Med f 1988;297:18-21.

cancer associated with mild dyskaryosis. Br Med $\mathcal{f}$ 1988;297:18-21.
9 Elwood JM, Cotton RE, Johnson J, Jones GM, Curnow J, Beaver MW. Are patients with abnormal cervical smears adequately managed? Br Med $\mathcal{J}$ 1984;289:891-4.

10 Prorok PC. Mathematical models and natural history in cervical cancer screening. In: Hakama M, Miller AB, Day NE, eds. Screening for cancer of the uterine cervix. Oxford: Oxford University Press, 1986:185-96.

\title{
Critical assessment of the use of growth monitoring for identifying high risk children in primary health care programmes
}

\author{
André Briend, Abdul Bari
}

Abstract

Objective-To see whether change in weight was a more useful index than weight for age in assessing the risk of dying among malnourished children.

Design-Prospective cohort study.

Setting-Rural community in Bangladesh being served by international health organisation.

Participants-1011 Children aged under 5, of whom 66 died.

End point-Efficient screening method for

The International Centre for Diarrhoeal Disease Research, Bangladesh André Briend, MD, nutritionist

Abdul Bari, MB, senior medical officer

Correspondence and requests for reprints to:

Dr A Briend, ICDDR, B, Box 128, Dhaka 1000 Bangladesh.

BrMed f 1989;298:1607-11 identifying malnourished children at risk of dying.

Measurements and main results-Weight was measured every month. Weight for age and monthly change in weight averaged over one and three months were calculated. Sensitivity and specificity curves were used to compare the values of these two variables in identifying children with a high risk of dying. Weight for age was more sensitive than change in weight at all levels of specificity. Changes in weight, however, were independently related to the risk of dying even when intercurrent diseases and low weight for age were taken into account.
Conclusions-For identifying children with a high risk of dying weight for age is a more efficient screening tool than a recent change in weight. Growth monitoring as currently recommended for primary health care programmes in developing countries does not seem to be the most effective approach in identifying children in need of urgent help.

\section{Introduction}

Growth monitoring is a key component of primary health care programmes aimed at bringing about a "child survival revolution" in the coming years.' The rationale for growth monitoring is that most mothers of malnourished children do not know that anything is wrong and that recognising abnormal growth will prompt them to take action to prevent their child's death. ${ }^{2}$ Though never stated explicitly, the concept underlying this approach is that children with low weight gain as detected by regular weighing are thought to be more at risk than those who are severely 
underweight and whose condition is therefore readily apparent to mothers. This assumption is reflected in the training of nutrition workers at the primary health care level by the emphasis put on the direction of the growth curves as compared with attained weight. ${ }^{3.8}$ To our knowledge, however, this hypothesis has never been validated, and we have therefore attempted to test it in a group of children aged under 5 from rural Bangladesh.

\section{Subjects and methods}

Data used for this analysis were collected during a study of the impact of rice based oral rehydration solutions on the nutritional state of children under $5 .^{9}$ The study area, straddling the Chandpur-Comilla highway, is located in the deltaic plain of Bangladesh, near the Meghna river, $70 \mathrm{~km}$ from Dhaka. This is a rural community which has been under demographic surveillance-since 1979. Growing rice, wheat, and jute is the main economic activity. The area was equally divided into three cells receiving different oral rehydration treatments for diarrhoea. The three cells were pooled for this analysis.

Data collection took place from October 1983 to October 1985. A total of 1011 children aged less than 36 months at the beginning of the study were included. The oldest children were aged 59 months or less at the end of the study. All children were weighed every month with portable spring scales (Salter, United Kingdom), which were read to the nearest $50 \mathrm{~g}$ and checked regularly with standard weights. Readings were always made at around the same time of day to minimise the effect of diurnal variations. Fieldworkers collected information about morbidity weekly and referred sick children to the project physician (A Bari) based in Chandpur. Diarrhoea was defined as the presence of three or more loose motions within 24 hours and acute respiratory infection as the simultaneous presence of two of the following: runny nose, cough, fever, and difficulty breathing. Tibial oedema was looked for by digital pressure over the tibia.

This analysis was made by using child months; a child was considered as a survivor if alive at the next visit and entered as a new child for the following month. In order to compare the relevance of changes in weight over different periods of time only intervals which were preceded by two weighings, one at one month and the other at three months before the beginning of the interval, were included in the analysis. This excluded most children below 6 months of age, mothers in this culture being reluctant to show young infants to outsiders. Intervals with complete information on recent weight gain represented $92 \%$ of the total.

Weight for age was calculated as the percentage of the median of standards recorded by the National Center for Health Statistics. ${ }^{11} 11$ Variations in weight and weight for age were adjusted by using the exact number of days between two visits to estimate the average monthly changes in weight over one and three months. Mean variations in weight were calculated to the nearest. $10 \mathrm{~g}$ with the assumption that averaging increased the precision of the results. ${ }^{12}$ Differences between means were tested with a two tailed $t$ test with separate estimates of variance. ${ }^{12}$ Relative risks were calculated with Miettinen test based confidence intervals. ${ }^{13}$ For each indicator sensitivity was defined for any cut off point as the proportion of children who died and who were below that cut off point at the last examination. Specificity was defined as the proportion of children who survived and who were above it. ${ }^{14}$ Curves were drawn for each indicator by plotting the sensitivity and specificity calculated for a wide range of possible cut off points. The performance of different indicators of nutritional state in assessing the risk of dying was evaluated by using these curves to compare their sensitivity for the same specificity level..$^{14}$

Maximum sum of sensitivity and specificity and normalised distances (differences expressed in terms of standard deviation (SD) units) between means for children who survived and those who died were calculated for each nutritional indicator. ${ }^{1+15}$ Normalised distances were compared by the $Z_{\mathrm{da}}$ test, as described by Brownie et al. ${ }^{16}$ This statistic, with a normal distribution, may be used to test whether one indicator is significantly more different than another between two groups of subjects. ${ }^{16}$ For multivariate analysis logistic regression was performed by using the statistical analysis system program. ${ }^{17}$ Significance of different risk factors was estimated by comparing the $\log$ likelihood statistic $(-2 \log$ likelihood ratio) of different logistic models. ${ }^{13}$ The predictive ability of different models was assessed by the $\mathrm{c}$ statistic. This statistic, which may vary from 0 to 1 , measures the degree of agreement between the observed outcome and the outcome predicted by a logistic model.

\section{Results}

Of a total of 20520 child months available for analysis, 66 ended with a non-accidental death and 20454 did not. Mean age at examination was 31 months (SD 12) among children who survived and 25 months (SD 9, range 6-43) among those who died $(\mathrm{p}<0.001)$. There was no clear seasonal pattern of deaths.

Weight for age, weight gain over one and three months, and variations of weight for age were all significantly different between the two groups (table I). Sensitivity and specificity curves of these different indicators showed that weight for age was superior to change in weight or variations in weight for age in assessing the risk of dying within the next month (figs 1 and 2). The maximum sum of sensitivity and specificity and normalised distance were greater for weight for age than for other indicators based on changes in nutritional state. When assessed with the $\mathrm{Z}_{\mathrm{da}}$ test the normalised distance between means of children who died and survived was found to be significantly greater for weight for age than for all other indices examined, with the exception of weight changes in the preceding three months (table I).

TABLE I-Weight for age, weight change, and variations in weight for age of children who died and those who survived

\begin{tabular}{|c|c|c|c|c|c|}
\hline Variable & $\begin{array}{c}\text { Survived } \\
(\text { mean }(\mathrm{SD})) \\
(\text { No of child months }=20454)\end{array}$ & $\begin{array}{c}\text { Died } \\
(\text { mean }(\mathrm{SD})) \\
(\text { No of child months }=66)\end{array}$ & $\begin{array}{l}\text { Normalised } \\
\text { distance } \\
(\%)\end{array}$ & $\begin{array}{l}\text { Maximum sum of } \\
\text { sensitivity and specificity } \\
(\%)\end{array}$ & $\mathrm{Z}_{\mathrm{da}} \neq$ \\
\hline Weight for age $(\%)$ & $70 \cdot 6(9 \cdot 5)$ & $52 \cdot 5(12 \cdot 6)$ & $1 \cdot 618$ & $161 \cdot 5$ & - \\
\hline Weight change in previous month (g) & $120(320)$ & $-180(440)$ & $0 \cdot 799$ & $142 \cdot 0$ & $4 \cdot 0^{\star \star}$ \\
\hline Weight change in previous 3 months (g) & $130(160)$ & $-140(240)$ & $1 \cdot 304$ & $154 \cdot 3$ & $1 \cdot 6(\mathrm{NS})$ \\
\hline Weight for age change in previous month (\%) & $-0 \cdot 16(2 \cdot 78)$ & $-2.37(3.65)$ & $0 \cdot 683$ & $135 \cdot 6$ & $3 \cdot 2 \star \star$ \\
\hline Weight for age change in previous 3 months ( $\%$ ) & $-0 \cdot 16(1 \cdot 42)$ & $-2 \cdot 16(2 \cdot 01)$ & $1 \cdot 147$ & $147 \cdot 7$ & $2 \cdot 1^{\star}$ \\
\hline
\end{tabular}

tAll differences between children who survived and died highly significant. $\neq$ Comparison of normalised distance between two groups with weight for age. ${ }^{\star} p<0 \cdot 05 .{ }^{\star \star} p<0 \cdot 01$ 
Children who lost weight in the previous months were more likely to have a lower weight for age than those who gained weight. This suggests that the relation between weight loss and risk of dying may be due to the low weight for age resulting from weight loss and not from weight loss itself. Moreover, sick children lose weight (table II). As sick children had a higher risk of dying (table III), this may also partly explain the relation between weight loss and risk of dying.

To test whether weight loss was associated with a higher risk of dying even when adjusted for final weight for age and concurrent diseases the relation between these different risk factors was examined by logistic regression analysis (table IV). Weight for age was transformed into a dichotomous variable, $60 \%$ of weight for age (the usual limit of severe malnutrition) being taken as a cut off point. ${ }^{18}$ The association of risk of dying with weight loss was still highly significant even when low weight for age and morbidity variables were included in these models. The relative risk associated with weight loss and low weight for age did not change substantially when children were divided into different age categories, when sex was taken into account, or when children who had diarrhoea were excluded from the analysis. No significant interaction was found between low weight for age and weight loss in models already including morbidity information. There was also no significant interaction between weight loss and age category.

To determine to what extent weight loss would improve a screening scheme already including low weight for age the sensitivities and specificities of different associations of risk factors were calculated. Associating two risk factors by an; "or" relation increased the sensitivity but decreased the specificity, and associations with an "and" relation had an opposite

TABLE II -Effect of selected diseases on monthly weight change

\begin{tabular}{|c|c|c|c|}
\hline & $\begin{array}{c}\text { Disease present } \\
(\text { mean }(\text { SD }))\end{array}$ & $\begin{array}{l}\text { Disease absent } \\
(\text { mean }(\mathrm{SD}))\end{array}$ & $t$ \\
\hline \multicolumn{4}{|l|}{ Diarrhoea: } \\
\hline Weight change in previous month $(\mathrm{g})$ & $10(330)$. & $170(310)$ & $32 \cdot 2^{\star \star \star}$ \\
\hline Weight change in previous 3 months $(\mathrm{g}) \dagger$ & $90(160)$ & $140(160)$ & $22 \cdot 1^{\star \star \star}$ \\
\hline \multicolumn{4}{|l|}{ Measles: } \\
\hline Weight change in previous month (g) & $-320(520)$ & $130(310)$ & $12 \cdot 8^{\star \star \star}$ \\
\hline Weight change in previous 3 months $(\mathrm{g}) \dagger$ & $-40(200)$ & $130(160)$ & $12 \cdot 3 \star \star \star$ \\
\hline \multicolumn{4}{|l|}{ Respiratory infections: } \\
\hline Weight change in previous month $(\mathrm{g})$ & $60(350)$ & $130(320)$ & $6 \cdot 1^{\star \star \star}$ \\
\hline Weight change in previous 3 months (g) & $90(160)$ & $130(160)$ & $7 \cdot 3 \star \star \star \star$ \\
\hline \multicolumn{4}{|l|}{ Oedema: } \\
\hline Weight change in previous month (g) & $70(370)$ & $120(320)$ & $1 \cdot 2(\mathrm{NS})$ \\
\hline Weight change in previous 3 months $(\mathrm{g}) \dagger$ & $40(160)$ & $130(160)$ & $3 \cdot 2^{\star \star}$ \\
\hline
\end{tabular}

†Weight changes over previous three months averaged on one month.

${ }_{\star \star}^{+W}<<0 \cdot 01 .{ }^{\star \star} \mathrm{p}<0 \cdot 0001$.

TABLE III - Relative risk of dying associated with different risk factors, expressed as relative risk of death within a month for children who had risk factor in month preceding interview

\begin{tabular}{|c|c|c|c|}
\hline & $\begin{array}{l}\text { Risk factor } \\
\text { present }\end{array}$ & $\begin{array}{l}\text { Risk factor } \\
\text { absent }\end{array}$ & $\begin{array}{c}\text { Relative risk } \\
(95 \% \text { confidence interval) }\end{array}$ \\
\hline \multicolumn{4}{|l|}{ Weight for age $<60 \%$; } \\
\hline No of child months & 2489 & $18031 !$ & \multirow{2}{*}{$14 \cdot 5(9 \cdot 8$ to $21 \cdot 3)$} \\
\hline No of deaths & 4 & $22 j$ & \\
\hline \multicolumn{4}{|c|}{ Weight loss in previous month: } \\
\hline No of child months & 5309 & $15211\}$ & $5.8 \quad(3.6$ to 9.0$)$ \\
\hline \multicolumn{4}{|c|}{ Weight loss in previous 3 months: } \\
\hline $\begin{array}{l}\text { No of child months } \\
\text { No of deaths }\end{array}$ & $\begin{array}{r}3329 \\
46\end{array}$ & $\left.\begin{array}{rl}17 & 191 \\
20\end{array}\right\}$ & $11 \cdot 1 \quad(7 \cdot 3$ to $16 \cdot 7)$ \\
\hline \multicolumn{4}{|l|}{ Diarrhoea: } \\
\hline $\begin{array}{l}\text { No of child months } \\
\text { No of deaths }\end{array}$ & $\begin{array}{r}6359 \\
17\end{array}$ & 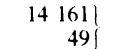 & $0.8(0.4$ to $1 \cdot 3)$ \\
\hline \multicolumn{4}{|l|}{ Measles: } \\
\hline $\begin{array}{l}\text { No of child months } \\
\text { No of deaths }\end{array}$ & $\begin{array}{r}223 \\
5\end{array}$ & $\begin{array}{r}202971 \\
61\}\end{array}$ & $7 \cdot 5 \quad(3 \cdot 4$ to $16 \cdot 2)$ \\
\hline \multicolumn{4}{|l|}{ Respiratory infections: } \\
\hline $\begin{array}{l}\text { No of child months } \\
\text { No of deaths }\end{array}$ & $\begin{array}{r}1118 \\
8\end{array}$ & $\begin{array}{r}194021 \\
581\end{array}$ & $2 \cdot 4(1 \cdot 2$ to $4 \cdot 9)$ \\
\hline \multicolumn{4}{|l|}{ Oedema: } \\
\hline $\begin{array}{l}\text { No of child months } \\
\text { No of deaths }\end{array}$ & $\begin{array}{l}77 \\
11\end{array}$ & $\begin{array}{r}20443\} \\
55\}\end{array}$ & $53 \cdot 1(37 \cdot 1$ to $76 \cdot 0)$ \\
\hline
\end{tabular}

TABLE IV-Risk of dying stratified by different risk factors as described by multivariate logistic regression models

\begin{tabular}{|c|c|c|}
\hline Variable & Odds ratio & $95 \%$ Confidence interval \\
\hline \multicolumn{3}{|l|}{ Model 1: } \\
\hline \multicolumn{3}{|c|}{-2 Log likelihood statistic: $781 \cdot 5, \mathrm{c}=0 \cdot 774$} \\
\hline \multicolumn{3}{|l|}{ Model 2: } \\
\hline Weight for age $<60 \%$ & $12 \cdot 0$ & $7 \cdot 2$ to $20 \cdot 2^{\star \star}$ \\
\hline $\begin{array}{l}\text { Weight loss in previous month } \\
-2 \text { Log likelihood }\end{array}$ & $\begin{array}{l}4 \cdot 3 \\
\text { tatistic: } 749 \cdot 0\end{array}$ & $\begin{aligned} 2.5 & \text { to } 7 \cdot 2^{\star \star} \\
0, \mathrm{c} & =0.821\end{aligned}$ \\
\hline \multicolumn{3}{|c|}{ Model 3: } \\
\hline Weight for age $<60 \%$ & $11 \cdot 7$ & 6.9 to $19 \cdot 9 \star \star$ \\
\hline Oedema & $30 \cdot 7$ & $14 \cdot 3$ to $66 \cdot 0^{\star \star}$ \\
\hline Respiratory infections & $2 \cdot 7$ & $1 \cdot 2$ to $5 \cdot 9 \star \star$ \\
\hline Measles & $5 \cdot 1$ & 1.9 to $14 \cdot 1^{\star \star}$ \\
\hline \multicolumn{3}{|c|}{-2 Log likelihood statistic: $722.9, c=0.831$} \\
\hline \multicolumn{3}{|c|}{$\begin{array}{l}\text { Model 4: } \\
\quad \text { Weight for age }<60 \%\end{array}$} \\
\hline Weight for age <60\% & $9 \cdot 7$ & $5 \cdot 7$ to $16 \cdot 6^{\star \star}$ \\
\hline Weight loss in previous month & $3 \cdot 7$ & $2 \cdot 1$ to $6 \cdot 3^{\star \star}$ \\
\hline Oedema & $26 \cdot 8$ & $12 \cdot 2$ to $59 \cdot 2^{\star \star}$ \\
\hline Measles & $3 \cdot 7$ & $2 \cdot 1$ to $6 \cdot 3^{\star}$ \\
\hline Respiratory infections & $2 \cdot 3$ & $1 \cdot 0$ to $5 \cdot 0^{\star}$ \\
\hline & tic. 69 & 0.936 \\
\hline
\end{tabular}

${ }^{\star} \mathrm{p}<0 \cdot 05 .{ }^{\star \star} \mathrm{p}<0 \cdot 001$.

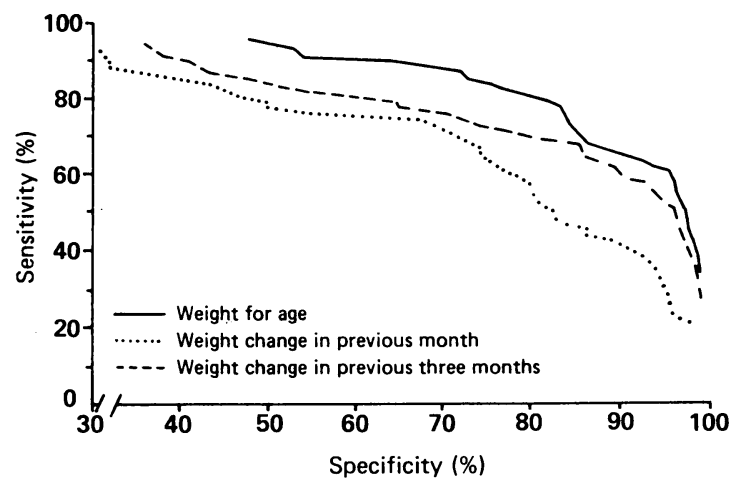

FIG 1-Sensitivity and specificity curves of weight for age compared with weight changes over one and three months in assessing risk of death

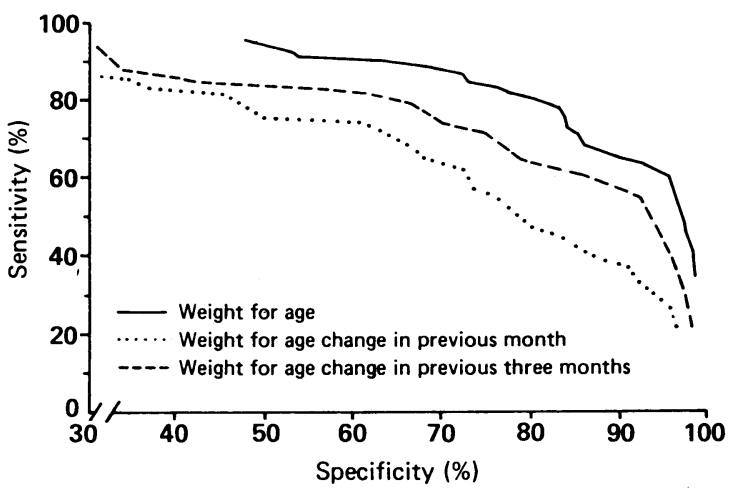

FIG 2-Sensitivity and specificity curves of weight for age compared with changes in weight for age over one and three months in assessing risk of death

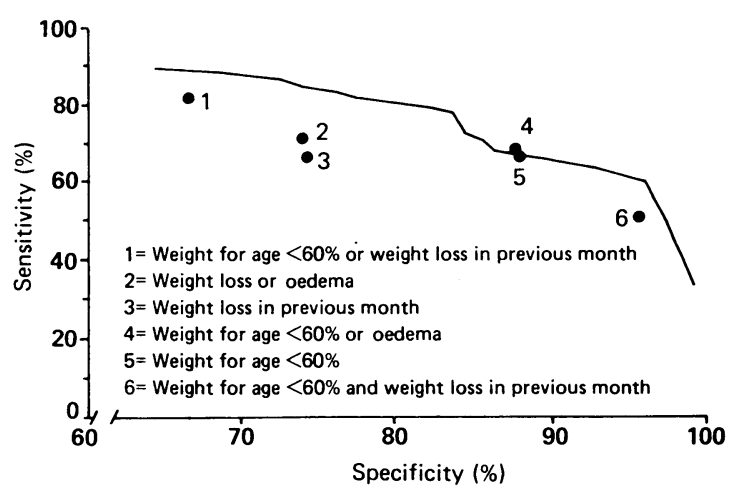

FIG 3-Sensitivity and specificity of different combinations of risk factors compared with weight for age 
effect. Nevertheless, with the exception of the association "low weight for age or oedema," which marginally improved the sensitivity of weight for age alone, all these associations of risk factors had lower sensitivities than weight for age considered alone for the same level of specificity (fig 3).

\section{Discussion}

In this study changes in weight and weight for age differed less between children who died and those who survived than weight for age itself. Weight gain was higher in young children, who also had a higher mortality. A confounding effect of age may to some extent explain the poor performance of change in weight to predict the risk of dying compared with attained weight for age. Yet introducing age in the logistic regression models did not change the relation between weight change and risk of dying. Moreover, variation in weight for age, a nutritional indicator that may be considered to be independent of age, also failed to recognise children with a high risk of dying more efficiently than variation in weight. The lack of significant interaction between age category and weight loss suggested that the severity of weight loss was independent of age, certainly in the age range 6-59 months.

Similar conclusions were obtained in another study from Bangladesh comparing weight changes over three months and weight for age in estimating the risk of dying in the next year. ${ }^{19}$ Nevertheless, as a result of small sample size, that study could not use variations in weight to assess the risk of death over a shorter period. Recently in a study from Zaire the researchers also concluded that decelerations in growth were of limited predictive power as a screening instrument to recognise children with a high risk of dying. ${ }^{20}$ Yet the possible confounding effect of infections-and especially measles, which accounted for $52 \%$ of the deaths $(8 \%$ in our study) and for the largest weight losses $^{21}$ - was not examined. Most likely the association between deceleration of growth and the risk of dying was overestimated in that study.

The poor performance of changes in weight and variations in weight for age as indicators of impending death may be due to errors in measurement. Errors grow larger when measuring a difference between two measures, considerably increasing the coefficient of variation. ${ }^{12}$ All efforts were made in this study to minimise errors in measurement, yet in a previous study in Bangladesh a standardisation exercise with the same scales as used here showed that the standard deviation due to variations in measurement amounted to $180 \mathrm{~g} .{ }^{22}$ In other settings it has been shown that in children non-nutritional factors such as intake of food and water, micturition, and defecation may induce day to day variations in weight with a standard deviation of $200 \mathrm{~g} .^{23}$ In age groups with an average monthly weight gain of less than $200 \mathrm{~g}$ these variations are likely to induce considerable errors. Measuring weight gain over three months may reduce the relative error but introduces delay in recognising risk.

If in this study the poor performance of changes in weight in detecting high risk children was due to variations in measurement then performance is bound to be even poorer in routine projects with less supervision of fieldworkers. The width of the $95 \%$ confidence interval of weight measurements in routine surveillance has been estimated to be often in excess of $1 \mathrm{~kg} .{ }^{24}$ In practice estimates of weight gain may be highly unreliable in primary health care projects.

Diarrhoea was not associated with a significant risk of death (table III), which is atypical of poor communities. This may be explained by the intensive oral rehydration programme which took place in the area during the study and by the referral of severe cases to the project physician or the nearby diarrhoea treatment facilities available from the International Centre for Diarrhoeal Disease Research, Bangladesh. This may have altered the relation between weight loss and risk of dying among children with diarrhoea, but excluding them from the analysis did not change the main conclusions.

Oedema was associated with a high risk of dying even when other risk factors were taken into account. This is in agreement with another study from Bangla$\operatorname{desh}^{25}$ and confirms the need to refer to a treatment facility any child with oedema found in the community. As oedema tends to mask recent weight loss, it may partly explain the poor performance of weight loss as compared with weight for age in assessing the risk of dying. The close value of the odds ratio of weight loss in logistic models with and without oedema (table IV), however, suggests that this effect is likely to be small.

Changes in weight were associated with a risk of dying even when low weight for age and selected diseases were controlled for. This supports the usual paediatric practice of taking into account recent weight change along with present weight for age and recent disease history when assessing the health of an individual child.

Some screening schemes use either low weight for age or weight loss to identify high risk children. ${ }^{6}$ This approach increases the sensitivity of screening, which is an advantage provided that resources for treating or referring children are not limited. This approach, however, also decreases the specificity of screening compared with low weight for age considered alone. A highly significant interaction term between low weight for age and weight loss in logistic regression models would indicate that this approach can give an interesting trade off between sensitivity and specificity. Our results, however, do not support this assumption and even suggest that such screening schemes have a lower sensitivity than weight for age alone for the same level of specificity. This is a serious disadvantage when resources are limited and only a small proportion of children can be helped.

Our results also suggest that combining weight for age and weight loss can improve the assessment of the risk of dying if they are used together to calculate a risk index using the coefficients of a logistic regression model. We do not know, however, to what extent the models found in this study are applicable to other settings. Moreover, determination of these coefficients is difficult. This is unfortunate, as unadapted coefficients may make the screening based on two indicators less effective as well as more cumbersome than if based on the most valuable indicator alone.

Mid-upper arm circumference may be used at the community level to give a rough estimate of nutritional state and is closely related to the risk of dying. ${ }^{2}$ Mid-upper arm circumference, however, is not precise enough to give a good assessment of growth and hence is usually not recommended for primary health care programmes. ${ }^{3-6}$ For identifying with a high specificity children at a high risk of dying this argument may be irrelevant: considering present nutritional state leads to more efficient screening than considering recent growth.

The field trial of rice based oral rehydration solutions was funded by Unicef and the Aga Khan Foundation. A Briend was on secondment from ORSTOM, Institut Français de Recherche Scientifique pour le Développement en Coopération. The International Centre for Diarrhoeal Disease Research, Bangladesh (ICDDR,B), is supported by countries and agencies which share its concern about the impact of diarrhoeal diseases on the developing world. Current 
important donors are: the Arab Gulf Programme, Australia, Bangladesh, Belgium, Canada, Denmark, the Ford Foundation, France, Holland, Japan, the Norwegian Agency for International Development, Saudi Arabia, Switzerland, the United Kingdom, Unicef, the United Nations Development Programme, USAID, the World Health Organisation, and the World Bank. We thank Dr A Foster and Dr J Menken for their help and advice in the statistical analysis and Drs $R$ Eeckels, V Fauveau, A Hall, and F Henry (ICDDR,B) for their help and encouragement during the preparation of the manuscript.

1 Anonymous. Growth monitoring: intermediate technology or expensive luxury? [Editorial]. Lancet 1985;ii:1337-8.

2 Morley D. Growth monitoring. In: Grant JP, ed. State of the world's children 1984. Oxford: Oxford University Press, 1983:77-81

Morley D, Woodland M. See how they grow: monitoring child growth for appropriate health care in developing countries. London: McMillan, 1979.

+ World Health Organisation. Guidelines for training community health workers in nutrition. Geneva: WHO, 1981. (Offset publication No 59.)

American Public Health Association. Primary health care issues: growth monitoring. Washington, DC: APHA, 1981.

6 Aga Khan Foundation. Primary health care technologies at the family and community levels. Geneva: Aga Khan Foundation, 1986.

7 World Health Organisation. The growth chart: a tool for use in infant and child care. Geneva: WHO, 1986.

Hebert JR. Growth monitoring: the "G" in GOBI-FFF. In: Cash R, Keusch $\mathrm{G}$, Lamstein J, eds. Child health and survival-the UNICEF GOBI-FFF program. London: Croom Helm, 1987:11-20.

9 International Centre for Diarrhoeal Disease Research, Bangladesh. Annual report 1986. Dhaka: ICDDR,B, 1987

10 National Center for Health Statistics. Growth curves for children, birth-18 years, United States. Vital Health Stat 1977;ser 11:No 165.
11 World Health Organisation Working (iroup. Use and interpretation of anthropometric indicators of nutritional status. Bull WHO 1986;64:929-4l.

12 Armitage P. Statistical methods in medical research. Oxford: Blackwell Scientific, 1971

13 Kleinbaum DG, Kupper LL, Morgenstern H. Epidemiological reseurch: principles und quantitative methods. Belmont, CA: Lifetime Learming Publications, 1982

14 Habicht JP, Meyers LD, Brownie C. Indicators for identifying and counting the improperly nourished. Am f Clin Nutr 1982;35:1242-54.

15 Cogill B. Ranking anthropometric indicators using mortality in rural Bangladeshi children, Ithaca, NY: Cornell University, 1983. (MSC thesis.) 16 Brownie $C$, Habicht JP, Cogill B. Comparing indicators of health and nutritional status. Am 7 Epidemiol 1986;124:1031-44.

17 SAS Institute. SUGI supplemental library user's guide, version 5. Cary, NC: SAS Institute, 1986.

18 Gomez F, Ramos-Galvan R, Frenk F, Cravioto JM, Chavez R, Vasquez J. Mortality in second and third degree malnutrition. $\mathcal{F}$ Trop Pediatr 1956;2 77-83.

19 Bairagi R, Chowdhury MK, Kim YJ, Curlin GT. Alternative indicators of mortality. Am f Clin Nutr 1985;42:296-306.

20 Kasongo Project Team. Growth decelerations among under-5-year-old children in Kasongo (Zaire). II. Relationship with subsequent risk of dying, and operational consequences. Bull WHO 1986;64:703-9.

21 Kasongo Project Team. Growth deceleration among under-5-year-old children in Kasongo (Zaire). I. Occurrence of decelerations and impact of measles on in Kasongo (Zaire). I. Occurrence of dec

22 Brown KH, Black RE, Becker S, Hoque A. Patterns of physical growth in a longitudinal study of young children in rural Bangladesh. Am f Clin Nutr 1982;36:294-302.

23 Zerfas AJ. Anthropometric field methods: general. In: Jelliffe DB, Jelliffe EFP, eds. Nutrition and growth. New York: Plenum Press, 1979:339-64.

24 Van Loon $H$. Epidemiology of malnutrition in developing countries. Louvrain: Katholieke Universiteit Leuven, 1987. (Thesis.)

25 Briend A, Woityniak B, Rowland MGM. Arm circumference and other factors in children at a high risk of death in rural Bangladesh. Lancet 1987;ii:725-8.

Accepted 7 April 1989)

\title{
Postoperative radiotherapy and late mortality: evidence from the Cancer Research Campaign trial for early breast cancer
}

\author{
J L Haybittle, D Brinkley, J Houghton, R P A'Hern, M Baum
}

Medical Research Council Trials Office, Cambridge CB2 2BW

$\mathrm{J}$ L Haybittle, PHD, honorary statistician

King's College Hospital, London

D Brinkley, FRCs, honorary consultant in radiotherapy and oncology

M Baum, FRCs, professor of surgery

Cancer Research

Campaign Clinical Trials

Centre, Rayne Institute,

London SE5 9NU

J Houghton, BSC, assistant director

R P A'Hern, MSC, statistician

Correspondence to: Mrs Houghton.

BrMed f 1989;298:1611-4
Abstract

Objective-To identify any excess mortality caused by adjuvant radiotherapy for early breast cancer.

Design-Prospective randomised clinical trial. Two thousand subjects needed for study to have a $\mathbf{9 0 \%}$ chance of detecting a difference in survival rate of $7 \%$ with $95 \%$ significance. Patients were followed up until June 1988, giving follow up of 158-216 months.

Setting-A multicentre trial mainly drawing patients from centres in the United Kingdom.

Patients -2800 Women presenting with clinical stage I or II carcinoma of the breast from June 1970 to April 1975.

Interventions-One group of women $(n=1376)$ had simple mastectomy followed by immediate postoperative radiotherapy (1320 to 1510 rets). The remaining women $(n=1424)$ had simple mastectomy with subsequent careful observation of the axilla, radiotherapy being delayed until there was obvious progression or recurrence of disease locally.

End point - Increased mortality in patients treated with radiotherapy from causes other than breast cancer.

Measurements and main results-Survival was measured from time of first treatment to death or last follow up. Deaths from any cause and from specified causes were counted as events. Comparison over the whole follow up showed a slight excess mortality in the group treated with radiotherapy (relative risk $1.04 ; 95 \%$ confidence interval 0.94 to 1.15 ). The relative risk of death from breast cancer was 0.97 $(0.87$ to 1.08$)$ but that of death from other causes was $1.37(1.09$ to 1.72$)$, the increase mainly being in women who had had tumours of the left breast (1.61
$(1 \cdot 17$ to $2 \cdot 24)$ ) and had been treated with orthovoltage (1.85 (1.27 to 2.71$))$. Analysis of causes of death after five years showed a relative risk of $2 \cdot 11$ $(1.25$ to 3.59$)$ for new malignancies and of $1.65(1.05$ to 2.58 ) for cardiac disease, the increase in cardiac mortality being most pronounced in patients who had had tumours of the left breast and whose treatment had included orthovoltage radiation (relative risk $2.67(1.28$ to $5 \cdot 55)$ ).

Conclusions - Adjuvant radiotherapy after simple mastectomy for early breast cancer produces a small excess late mortality from other cancers and cardiac disease. The risk has to be balanced against the higher risk of local recurrence when immediate postoperative radiotherapy is not given. The balance has to be assessed for each patient, and for many patients radiotherapy will still be desirable in the initial treatment of their early breast cancer.

\section{Introduction}

Postoperative radiotherapy reduces the rate of local recurrence after treatment for early breast cancer. ${ }^{2}$ No significant improvement in rates of survival has been shown after radiotherapy, and some critics have claimed that it has a deleterious effect. ${ }^{3}$ Cuzick et al carried out an overview of 10 randomised trials in which the difference between the two groups was solely whether patients had been irradiated postoperatively. ${ }^{+}$ This overview showed no significant effect on survival up to 10 years, but beyond 10 years the mortality in the irradiated patients was signficantly increased. This finding was greatly. influenced by the earlier trials, which contributed most to the long term follow up and tended to use orthovoltage rather than supervoltage radiation. 